\title{
0 profissional de apoio e a inclusão de alunos público-alvo da educação especial
}

\author{
The support professional and the inclusion process of public pupils \\ target of special education
}

\section{El profesional de apoyo e el proceso de inclusión de alumnos público- punto de la educación especial}

\author{
Denise Macedo Ziliotto' \\ Universidade La Salle, Programa de Pós-graduação em Educação, Professora e \\ pesquisadora. \\ https://orcid.org/0000-0001-9146-5425 \\ Amanda Burchert ${ }^{2}$ \\ Universidade La Salle, Pesquisadora voluntária. \\ https://orcid.org/0000-0002-5653-0081
}

Resumo: 0 artigo teve como objetivo analisar a atuação do profissional de apoio (PA) no processo de inclusão de alunos público-alvo da Educação Especial no ensino público fundamental. A normativa jurídica relativa ao PA é recente e demanda especificidades, observando-se que as funções desenvolvidas por esse profissional são diversas nos contextos escolares. A pesquisa possui natureza qualitativa e exploratória e teve como instrumentos para coleta de dados entrevistas com profissionais de apoio, planos municipais de educação e legislação atinente ao objeto de estudo. 0 campo de investigação escolhido remete-se às escolas de ensino fundamental públicas localizadas em municípios do Estado do Rio Grande do Sul (RS), sendo os dados analisados sob a perspectiva hermenêutica. Os resultados indicam a predominância de estudantes de graduação como estagiários ou monitores para atuarem como profissionais de apoio, não havendo identificação ou escolha inicial do trabalho com a Educação Especial. 0 atendimento é direcionado a um ou dois alunos em sala de aula, abarcando atividades de planejamento, ensino, adaptação e produção de materiais, caracterizando uma condução pedagógica no apoio realizado. Observa-se que a relação dos alunos com o professor, com os colegas e demais participantes da escola é restrita, configurando uma vinculação majoritária com o PA. No contexto investigado, a criação do dispositivo de apoio não assegura a condição inclusiva, remetendo o atendimento do aluno referencialmente ao profissional que the assiste, permeado por inconsistências

Pós-doutora em Educação pela Universidade de Lisboa; Doutora em Psicologia Social pela Universidade de São Paulo.

Mestre em Educação, na linha de pesquisa Gestão, Educação e Políticas Públicas, pela Universidade La Salle; Graduada em Gestão de Recursos Humanos pela Universidade La Salle. 
na oferta educativa e pela restrita convivência inclusiva com a turma e com a comunidade escolar como um todo.

Palavras-chave: Escolas públicas. Inclusão. PA.

Abstract: The article aims to analyze the performance of the Support Professional (PA) in the Process of inclusion of public-targeted students of special education in public education fundamental. The legal regulations relating to the support professional are recent and specific demands, observing that the functions developed by these professionals are diverse in school contexts. The research has a nature qualitative and exploratory, and had as instruments for data collection interviews with support professionals, municipal education plans and legislation regarding the object of study. The field of selected research refers to public elementary schools located in municipalities of the state of Rio Grande do Sul (RS), and the data analyzed under the hermeneutic perspective. The results indicate the predominance of students of trainees or monitors to act as PAs, with no ldentification or initial choice of work with special education. The service is to one or two students in the classroom, covering activities of planning, teaching, adaptation and production of materials, characterizing a pedagogical conduction in the support carried out. It is observed that the relationship of students with the teacher, with colleagues and other participants of the school is restricted, defining a majority linkage with the PA. In the context investigated, the creation of the support device doesn't ensure the inclusive condition, referring the attendance of the student referred to the professional who assists him, permeated inconsistencies in the educative offer and the limited inclusive coexistence with the class and with the school community as a whole.

Keywords: Public schools. Inclusion. Professional support.

Resumen: El artículo tiene como objetivo analizar la actuación de el profesional de apoyo (PA) en el proceso de inclusión de alumnos público objetivo de la educación especial en la enseñanza pública fundamental. La normativa jurídica relativa al profesional de apoyo es reciente y demanda especificidades, observándose que las funciones desarrolladas por este profesional son diversas en los diferentes contextos escolares. La investigación posee naturaleza cualitativa y exploratoria, y tuvo como instrumentos para la recolección de datos entrevistas con profesionales de apoyo, planes de educación municipal y legislación sobre el objeto de estudio. El campo de investigación elegido se remite a las escuelas de enseñanza fundamental públicas ubicadas en municipios del estado del Rio Grande do Sul (RS), siendo los resultados analizados bajo la perspectiva hermenéutica. Los resultados indican predominancia de estudiantes de graduación como pasantes o monitores para actuar como PAs, no habiendo identificación o elección inicial del trabajo con educación especial. La atención se dirige a uno o dos alumnos en el aula, abarcando actividades de planificación, adaptación y producción de materiales, enseñanza, caracterizando una conducción pedagógica en el apoyo realizado. Se observa que la relación de los alumnos atendidos con el profesor, con los colegas y demás participantes de la escuela está restringida, así como las potencialidades de aprendizaje de los estudiantes, en la evaluación de las PAs. El contexto de la actuación del profesional de apoyo investigado evidencia la 
creación de dispositivos legales muchas veces desatendidos de politicas que aseguren la inclusión, de modo que la creación de cargos y recursos no fragmente la propuesta de atención al alumno de la educación especial, sino contrariamente, concretice una posibilidad y actuación multiprofesional en red. Palabras-clave: Escuelas públicas. Inclusión. Profesional de apoyo.

Recebido em 11 de junho de 2019

Aceito em 6 de fevereiro de 2019

Publicado em 22 de junho de 2020

\section{INTRODUÇÃO}

Pensar em inclusão remete à diversidade dos seres humanos, pois mesmo tendo direitos iguais, há importantes diferenças que devem ser respeitadas e estar presentes na sociedade, essencialmente na educação escolar (MACED0 et al., 2014). Para isso, no ambiente educacional é importante refletir se os alunos estão se desenvolvendo e vivendo seus processos de ensino e aprendizagem de acordo com suas diferenças $A$ inclusão não se resume a projetos, às necessidades individuais ou mesmo à definição de lugares ditos como regulares ou especiais. Incluir é fazer o que é direito e essencial para cada pessoa, respeitando os momentos de sua vida, as suas diferenças e capacidades (SILVA; MACIEL, 2011).

Segundo Frohlich (2018), pode-se compreender a inclusão como a necessidade de fazer com que as pessoas participem das diferentes ações, implicando a participação de todos e sendo, portanto, difícil dizer quem são os excluídos. A palavra exclusão é usada para compreender o outro da inclusão (VEIGA-NETO; LOPES, 2011, p. १२2):

\footnotetext{
[...] excluídos refere-se àqueles que, de alguma maneira, são discriminados pelo Estado e/ou pela sociedade. Se os espaços sociais não são ocupados por todos, é porque alguns, em seu próprio benefício, operaram uma intervenção espúria, uma distribuição anômala. Incluir significa, então, restaurar uma ordem natural perdida, isso é, voltar a um estado original que seria próprio do mundo e, bem por isso, da própria natureza dos seres humanos.
}

Concebendo o processo de inclusão como garantia dos direitos da condição cidadã, e reconhecendo a complexidade da dinâmica inclusiva/excludente, torna-se relevante situar o contexto que problematizou e ensejou o desenvolvimento da investigação. De acordo com o censo escolar de 2018 (INEP, 2019) as matrículas da educação especial - alunos com deficiência, transtornos globais do desenvolvimento, altas habilidades - na Educação Básica 
chegou a 1,2 milhão, configurando um aumento de 33,2\% em relação a 2014. 0 percentual de alunos incluídos em sala de aula regular em 2014 era de 87,1\%, em 2017 representava 90,9\% (INEP, 2018) e em 2018 chegou a 92,1\%, evidenciando-se aumento gradativo dos estudantes, creditado ao aumento de matrículas no ensino médio, que dobraram no período (INEP, 2019) . Se o número de sujeitos incluídos é representativo, torna-se importante analisar como esse processo tem sido vivenciado e a sua efetividade.

Esse aumento do número de alunos com deficiência nas escolas advém de ações e políticas do governo e da sociedade civil, que assinalam a educação como direito fundamental. Nesse escopo, há dispositivos engendrados nesse processo de construção da escola inclusiva, como o Atendimento Educacional Especializado (AEE), as salas de recursos, as capacitações docentes e o profissional de apoio (PA), responsável pelo suporte aos alunos público-alvo da Educação Especial incluidos no ensino regular. Ainda recente em sua experiência e consequente análise, o profissional de apoio é alguém muito próximo no acompanhamento do estudante. Sua função e atuação não estão claramente definidas, havendo divergência entre os documentos legais, o que concorre para uma multiplicidade de configurações de atividades aos alunos, ensejando a reflexão sobre os efeitos desse contexto. Fonseca e Bridi (2016) identificaram um número reduzido de publicações que têm como temática o PA, compreendendo tal resultado como um reflexo de uma ação recente no espaço escolar. Considerando esse escopo, o objetivo da investigação é analisar a atuação dos profissionais de apoio no processo de inclusão de alunos público-alvo da Educação Especial no ensino público fundamental, com intuito de contribuir para a construção de uma escola para todos.

Para a consecução dos objetivos foi desenvolvida pesquisa qualitativa exploratória em escolas de ensino fundamental públicas localizadas em cinco municípios da região CentroSul do Estado do Rio Grande do Sul. Os instrumentos utilizados para coleta de dados foram entrevistas com profissionais de apoio, os planos de educação dos municípios e a legislação atinente ao objeto de estudo, analisados sob a perspectiva hermenêutica, que privilegia a constante e múltipla interpretação dos dados.

\section{MARCOS LEGAIS RELATIUOS AOS APOIOS À INCLUSÃO}

A Lei de Diretrizes e Bases de 1996, em seu artigo 58, entende como Educação Especial a oferta na rede regular de ensino, bem como quando necessário, de serviços de apoio especializados para atender às necessidades dos alunos da Educação Especial (BRASIL, 1996). Complementando, o artigo 59 da LDB enfatiza que os sistemas de ensino 
garantirão aos alunos currículos, técnicas, recursos e a organização específica para suprir suas necessidades. (BRASIL, 1996). No artigo 208 da Constituição Federal, o inciso III refere que o dever do Estado com a educação é garantir o atendimento educacional especializado às pessoas com deficiência, em especial na rede regular de ensino (BRASL, 1988), o que compreende a utilização de recursos em sala de aula que facilitem e concorram para o processo de aprendizagem e inclusão dos alunos. Posteriormente, as Diretrizes Nacionais da Educação Especial na Educação Básica determinam a oferta de serviços de apoio pedagógico nas classes comuns, contemplando a participação colaborativa do professor especializado na Educação Especial, de professores intérpretes ou professores itinerantes, havendo também a previsão de outros apoios ligados a aprendizagem, comunicação e locomoção (BRASIL, 2001).

No ano de 2008 foi publicada a Política Nacional de Educação Especial na Perspectiva da Educação Inclusiva, que busca garantir a inclusão escolar dos sujeitos com deficiência, transtornos globais do desenvolvimento e superdotação, por meio da orientação aos sistemas de educação, para que haja inclusão no ensino regular, desde a educação infantil até o ensino superior, com atendimento educacional especializado e profissionais para a educação inclusiva. 0 documento delimita ser função dos sistemas de ensino a organização da Educação Especial, disponibilizando intérpretes, guias e monitor ou cuidador dos alunos que necessitam de apoio em funções como higiene, locomoção e alimentação, além de outras atividades que requeiram ajuda no ambiente escolar (BRASIL, 2008).

No contexto federal, a Nota técnica SEESP/GAB n 19, de 2010, é a primeira menção à nomenclatura PA. Inicialmente definiu que as escolas devem oferecer profissionais de apoio na Educação Especial para promover acessibilidade e ajudar os alunos com necessidades em aspectos relacionados a locomoção, higiene, comunicação e alimentação. A Nota indica que não é função do PA desenvolver atividades diferentes para o aluno com deficiência, nem ser responsável pelo ensino ao estudante. Também menciona que esse profissional deve trabalhar de forma alinhada com os docentes da sala de aula regular e da sala de recursos multifuncionais (BRASIL, 2010).

A Nota Técnica $n^{\circ} 24$, de 2013, afirma que o serviço do PA deve ser uma medida utilizada sempre que houver necessidade de apoio individual ao aluno, buscando acessibilidade à comunicação e cuidado com alimentação, higiene e locomoção. 0 documento também destaca alguns elementos da oferta desse profissional: 0 apoio se destina aos alunos que não exerçam as atividades relacionadas anteriormente com independência e quando a dificuldade do aluno não é atendida no contexto geral da assistência aos demais alunos. Esse apoio não substitui a escolarização ou o Atendimento Educacional Especializado (AEE), sendo articulado com a sala de aula regular, a sala de recursos e outras atividades e avaliado pela escola junto com a família em sua efetividade (BRASIL, 2013). 
Mais recente, a Lei Brasileira de Inclusão, de 2015, em seu artigo 3, inciso XIII, define o PA como o sujeito que realiza funções de auxilio à alimentação, higiene e locomoção e que trabalha em todas as atividades do ambiente escolar, em qualquer nível de ensino e instituição. No artigo 24, inciso XVII, a lei garante a oferta de profissionais de apoio em sala de aula (BRASIL, 2015).

A ideia de um serviço na sala de aula regular para auxiliar com os alunos públicoalvo da Educação Especial se manteve ao passar dos anos, o que mudou é a forma como esse apoio é oferecido, de maneira que os cuidados pessoais ganharam mais visibilidade, e o apoio à aprendizagem se tornou pouco evidenciado (SCHREIBER, 2012). No entender de Garcia (2016), essa mudança da política ocorre em decorrência da relação custo-benefício: ter um professor de Educação Especial em sala de aula na qual existe um aluno público-alvo da Educação Especial não é razoável na lógica econômica; assim, não se refere à falta de recursos, mas à maneira como eles são alocados e à intencionalidade de sua atuação.

Uma das ações de inclusão é o AEE, que identifica e elabora soluções pedagógicas que concorrem para garantir a efetiva participação dos alunos na escola, levando em conta a singularidade e as necessidades dos estudantes. As atividades que são realizadas no AEE são diferentes daquelas realizadas em sala comum, porém não substituem a escolarização, porque esse atendimento deve ser complementar para a sua formação (BRASIL, 2008). A oferta deve estar prevista no projeto pedagógico da escola, o qual é exercido na sala de recursos, que se caracteriza por um espaço físico composto por móveis, equipamentos espećíicos e materiais didáticos. Também é prevista a interação com outros profissionais, como intérprete de libras, guias e outros, que auxiliem no apoio de atividades de alimentação, higiene e locomoção (BRASIL, 2009), e esse atendimento deve acontecer em turno diferente ao horário de aula. Segundo Garcia (2013, p. 108):

\footnotetext{
Define-se o professor do AEE como profissional docente com formação específica, não mais definido como "especializado". Para além do professor do AEE, outros profissionais são elencados: intérprete de libras, instrutor de libras, monitor/tutor, e o próprio professor regente das turmas de educação básica, o qual precisa ter em sua formação contato com conteúdos que favoreçam a prática pedagógica com os alunos da Educação Especial.
}

$0 \mathrm{AEE}$ acontece nas salas de recursos multifuncionais (SRM), que também compõem as ações inclusivas presentes nas escolas. A SRM tem natureza pedagógica e é utilizada por um professor especializado que suplementa e complementa a educação em sala comum do ensino regular. 0 desenvolvimento e a execução das metas do AEE são de responsabilidade dos docentes que atuam na SRM, em conjunto com os professores do ensino regular, famílias e outros serviços, como saúde e assistência social (BRASIL, 2009). 
Tendo situado o escopo do AEE e das SRM, explicita-se a distinção entre a atuação do professor de apoio e o PA. Segundo Carvalho (2009), a função do professor de apoio consiste, predominantemente, na atuação com os alunos público-alvo da Educação Especial. Outra função é apoiar os professores regulares, além de atuar na formação e coordenação de processos educativos. 0 apoio ao professor regular pode provocar mudanças na forma de atuação e na qualidade da educação ofertada a todos os alunos; pode também auxiliar o professor regular a adquirir competências para atuar com os alunos com deficiência. 0 trabalho cooperativo ajuda no desenvolvimento pessoal e profissional do professor regular e do professor de apoio.

Neste artigo, a concepção de professor de apoio alinha-se com o entendimento de Freitas (2013) e Carvalho (2009), que o concebem como o profissional que possui formação superior e/ou alguma especialização em Educação Especial, sendo responsável, juntamente com o professor regente, pelo ensino e aprendizagem dos sujeitos. 0 professor de apoio auxilia o docente no planejamento e adaptação das aulas, garantindo que os alunos sejam incluídos em todas as atividades, atuando de forma colaborativa com o professor regente.

\section{O PROFISSIONAL DE APOIO À INCLUSÃO}

0 PA é uma denominação e atribuição recente no processo de construção da escola inclusiva, e há várias denominações para esse profissional - facilitador, tutor, mediador. Esta última - mediador - seria, para Mousinho et al. (2010), o termo que mais explica o papel do profissional que acompanha a criança em sala regular. A atuação do PA é articulada com professores regentes, professores da SRM e todos os profissionais da escola em busca da efetividade da inclusão escolar (ARAÚJO; XAVIER; FREITAS, 2017). Silva e Maciel (2011) entendem que o profissional de apoio também é um auxílio para os professores, pois é ele que acompanha diretamente o aluno público-alvo da Educação Especial e pode dar contribuições ao professor sobre o desenvolvimento do aluno. Schreiber (2012, p. 91) assinala que "0 PA, na sua origem, não é proposto com o intuito de auxiliar o professor regente da classe comum [...] já que as funções delegadas ao professor envolvem o ensino de elementos importantes para o desenvolvimento pessoal e acadêmico dos alunos."

Fonseca (2016) assinala que documentos como legislações, notas técnicas e pareceres designam a atuação do PA, como apoio a higiene, locomoção e alimentação, podendo, também, desenvolver outras atividades. Porém, não é definido o que são essas outras atividades, as quais podem ter diversas interpretações, as quais têm efeitos no cotidiano da escola. Ao investigar o PA no âmbito da escola particular, o autor identificou 
uma diversidade de contextos no que se refere a contratação, folha de pagamento dos profissionais e atividades que são exercidas na escola. Fonseca (2016) também identificou a pluralidade na formação educacional dos profissionais de apoio: Educação Especial, psicologia, pedagogia, educação física, em curso ou com graduação concluída. Ainda com relação ao acompanhamento do PA, em algumas escolas esse processo é realizado pela professora da Educação Especial, em outras, pela direção, e em alguns casos ocorre o monitoramento pela família do aluno.

A presente investigação tem como escopo o apoio na rede de ensino pública municipal do ensino fundamental, podendo explicitar elementos atinentes a esse contexto, visto que a presença desse profissional é uma realidade nas escolas, especialmente em razão do aumento de alunos público-alvo da Educação Especial em classes regulares e da presença de estudantes com deficiência no ambiente educacional. A seguir é descrito o percurso investigativo da pesquisa de campo realizada, que visa responder aos objetivos inicialmente propostos.

\section{PERCURSO INUESTIGATIUO}

Considerando o objetivo da pesquisa - analisar a atuação dos profissionais de apoio no contexto da escola pública inclusiva de ensino fundamental -, o delineamento da investigação é de natureza qualitativa e exploratória, já que não há produção acadêmica ampla sobre o tema de investigação, buscando-se produzir conhecimentos sobre o objeto investigado. A pesquisa exploratória, para Gil (2012), tem como objetivo esclarecer e desenvolver ideias que servem para futuras pesquisas, formulando e encontrando novos problemas. Segundo Marconi e Lakatos (2003), a pesquisa exploratória tem três finalidades: gerar hipóteses, conhecer mais sobre o assunto pesquisado e atualizar conceitos.

A região Centro-Sul do Rio Grande do Sul foi escolhida como campo de pesquisa, sendo também conhecida como Costa Doce, pelas condições do turismo, havendo a predominância das culturas alemã, polonesa e italiana na sua formação populacional. A agricultura, a pecuária, o turismo e o comércio são as principais atividades econômicas dessa região. Elegeu-se esse contexto porque é de acesso da pesquisadora e por serem restritas as investigações acadêmicas neste escopo - municípios do interior do Estado com população de 3.693 a 62.759 habitantes. 0s critérios de inclusão utilizados para a composição da amostra foram: a escola deveria ser pública, de ensino fundamental, possuir profissionais de apoio e haver consentimento da secretaria da educação do município. A coleta de dados foi realizada em cinco escolas públicas, compreendendo diferentes cidades da região, sendo 
adotada a saturação como indicativo da potencialidade da coleta de dados (FONTANELLA; RICAS; TURATTO, 2008).

Inicialmente foram feitos contatos telefônicos e por e-mail com as secretarias de educação de alguns municípios da região escolhida, sendo os critérios de escolha das cidades o acesso e o retorno ao e-mail ou contato telefônico. A partir dos contatos, foram explicitados os objetivos da investigação e solicitou-se a realização da pesquisa nas escolas, as quais, posteriormente, foram indicadas pelos secretários de educação, oportunizando, então, o agendamento das entrevistas com os profissionais de apoio, realizadas no ambiente de trabalho dos participantes.

Como fontes secundárias foram analisadas legislações federais e estaduais relacionadas aos apoios à inclusão e os planos de educação dos municípios onde a investigação foi desenvolvida, por sua importância enquanto documentos norteadores para a elaboração dos projetos políticos pedagógicos das escolas, em cumprimento às diretrizes do Plano Nacional de Educação (BRASIL, 2014).

Após a pesquisa de campo e a coleta de dados, foi realizada a análise hermenêutica, que enfatiza a interpretação e a posição do investigador. Stein (2004, p. 19) enfatiza que "As estruturas lógicas não dão conta de todo o nosso modo de ser conhecedores das coisas e dos objetos, e ai somos obrigados a introduzir um elemento que será o núcleo dessa análise, o elemento da interpretação." A partir da análise sistemática das entrevistas e dos documentos, bem como das discussões produzidas no grupo de pesquisa em que as investigadoras se inserem, foram identificadas as questões apresentadas a seguir.

\section{APRESENTAÇÃO E DISCUSSÃO DOS DADOS}

A coleta de dados abarcou três fontes: as leis e normativas relativas ao PA, os planos municipais de educação das cidades investigadas e as entrevistas com as profissionais atuantes nas escolas. A dimensão jurídica subsidiou a revisão teórica, possibilitando o mapeamento das diretrizes existentes em nível nacional e regional. A pesquisa de campo ocorreu entre março e abril de 2018, a partir do contato inicial com secretarias de educação de municípios da região escolhida e do contato direto da pesquisadora com as escolas. As informações coletadas originaram o acesso aos planos municipais de educação referentes dos municípios, que foram analisados na perspectiva das diretrizes referentes ao PA, e as entrevistas nas escolas com as participantes.

Referente aos planos municipais de educação (PME) - que possuem vigência de 2015 a 2025 -, os cinco documentos mencionam o comprometimento com a oferta de salas 
de recursos multifuncionais, atendimento educacional especializado e cursos de formação continuada para os docentes. Observa-se que os planos seguem metas e estratégias alinhadas ao contexto da Educação Especial, tendo como balizadoras as legislações estaduais e federais. Porém, somente em três documentos o PA é mencionado entre as estratégias para a educação inclusiva. 0 texto é bastante semelhante, explicitando que, dentre as ações para concretizar a Meta 4 do Plano Nacional de Educação (BRASIL, 2014), é prevista a ampliação de equipes para o atendimento de estudantes com deficiência, transtornos globais do desenvolvimento e altas habilidades em seu processo de escolarização, com expressa menção aos profissionais de apoio ou auxiliares, e também nominando professores de AEE, tradutores(as) e intérpretes de Libras, guias-intérpretes para surdos-cegos, professores de Libras, prioritariamente surdos, e professores bilíngues. Não foram identificadas normativas ou outros documentos que definam a atuação do PA em nível municipal, o que concorre para a não especificidade do perfil do profissional, bem como das atividades que ele desenvolve nas escolas.

A seguir são apresentadas as entrevistadas, identificando-as pelas siglas E1, E2, E3, E4 e E5 para que seja preservado o anonimato.

\begin{tabular}{cccccc}
\multicolumn{6}{l}{ Tabela 1 - Identificação das entrevistadas } \\
\hline Ent & Idade & Formação & Tempo atuação & Denominação & Contrato \\
\hline E1 & 19 & Letras & 10 meses & Monitora & Estágio \\
E2 & 25 & Biologia & 4 meses & Monitora & Estágio \\
E3 & 20 & Pedagogia & 12 meses & Monitora & Estágio \\
E4 & 22 & Psicologia & 24 meses & Monitora & Estágio \\
E5 & 49 & Pedagogia & 24 meses & Monitora & Concurso \\
\hline
\end{tabular}

Fonte: os autores.

Para preservar o anonimato das participantes, não há identificação da cidade em que atuam, mas a escolha foi intencional ao se observar a representação de diferentes municípios da região. Todas as participantes que atuam como PAs são mulheres, reafirmando um traço predominante no exercício da educação no ensino fundamental. As entrevistadas, exceto E5, são estudantes de cursos de graduação e vinculam-se à atividade de PA como estagiárias. Em razão da diversidade da formação, possivelmente não há especificidade quanto às licenciaturas ou exigência de experiência anterior no âmbito escolar. 0 prazo máximo de contrato é de 24 meses, o que sinaliza a finalização da atividade de E4 na escola. Os municípios utilizam contratos de estágios para preencherem os quadros de PA, e os universitários buscam o estágio para cumprirem exigências de sua formação, obterem 
fonte de renda e se aproximarem do contexto escolar. Assinala-se que essa modalidade predominante de contrato incorre no caráter temporário da atuação e na possível intenção pedagógica da experiência - ao remeter-se às licenciaturas -, o que não coincide com as atribuições previstas para essa função do ponto de vista legal.

E5 não corresponde a essas características: atua na escola há 24 anos, e há dois também trabalha como monitora, sendo concursada pelo município. Possui duas graduações, cursa pós-graduação em Educação Inclusiva e fez capacitações sobre autismo e AEE. Sua vinculação é justificada por meio de um desdobramento contratual, pois pela manhã é monitora de inclusão e à tarde trabalha como professora titular.

As implicações dessas diferentes configurações contratuais, advindas de trajetórias de trabalho e formações distintas, acabam por se equalizarem na denominação do cargo - monitora - e nas práticas e posicionamentos, como explicitado a seguir.

\subsection{ATUAÇÃO COMO PROFISSIONAL DE APOIO}

Inicialmente são apresentados os contextos da atuação das participantes como PAs, observando-se que, exceto $E 5$, todas ingressaram na atividade a partir da exigência de práticas atinentes à formação acadêmica. Importante mencionar que nas trajetórias de profissionalização das entrevistadas não havia a intencionalidade na atuação com alunos público-alvo da Educação Especial, tendo sua inserção nesse contexto diante das contingências de estágio ou de exercício profissional, sendo percebido inicialmente com surpresa, como algo inusitado em seu percurso de formação.

El começou a atuar nessa área porque buscava um estágio, quando então the foi apresentado um menino que teria que acompanhar, referindo que "[...] foi bem diferente porque não é o que eu esperava, foi uma surpresa boa." E2 atuou em turma com alunos públicoalvo da Educação Especial, com um menino de oito anos, e enfrentou dificuldades no primeiro mês de trabalho: "No início ele teve dificuldade em me aceitar, ele tinha outra monitora, e a gente fazia a troca de monitoras, para ele se acostumar com duas pessoas." E3 nunca tinha trabalhado com crianças, sendo o estágio seu primeiro contato com alunos, afirmando que "[...] é uma coisa muito boa, tu te sentes viva. Eles te ensinam muita coisa, além de tu ensinares muito para eles, eles te ensinam muito." Também refere que foi muito bem recebida na escola, porque como era nova, tudo era estranho, mas é algo que ela gosta, "[...] é bom estar com eles, é bom ensinar." (informações verbais).

A inserção de E4 como monitora decorre da busca de experiência com crianças, relatando que: "No começo foi bem desafiador, porque logo já peguei uma criança bem 
complicada. Então foi difícil, tem todo um processo de conhecer a escola, como funcionava, mas nos primeiros dois meses de adaptação já estava funcionando bem." (informação verbal). E5 iniciou sua atuação como monitora em razão do desdobramento de seu contrato de trabalho, pois havia uma aluna com microcefalia que ingressou na escola, já que na Associação de Pais e Amigos dos Excepcionais (APAE) não há educação formal. Essa estudante cadeirante precisava de auxílio nas atividades de higiene e alimentação, tarefas que eram de sua responsabilidade. Das cinco entrevistadas, somente E5 atua como monitora e professora.

Diferente de E5, as outras entrevistadas, estudantes de graduação, não possuíam experiência anterior com crianças, no contexto escolar ou com alunos público-alvo da Educação Especial. Suas considerações refletem o desafio e as dificuldades ao iniciarem sua atuação na escola, circunscritos às especificidades do ambiente educacional, do aluno da educação especial e da responsabilidade para com o aprendizado do aluno, concebido como de sua atribuição. A inserção, que ocorre a partir de uma denominação inespecífica monitor - também não é delimitada pela descrição de suas atividades, o que concorre para a identificação majoritária às funções pedagógicas no contexto investigado, permitindo uma construção bastante individual das práticas, como se evidencia no relato a seguir:

\footnotetext{
Mas não é que tenha que ter formação, porque quando tu chegas na escola, a lei exige que tem que ter um monitor, mas não diz que o monitor tem que ser especializado. A maioria das escolas nem monitores tem, então o que acontece? No ano passado, que a monitora do aluno era uma menina do magistério que estava fazendo horas - era a monitora que ele tinha ajudava bastante, mas não tem a experiência, não tem curso de como lidar com eles, e também ela fazia como eu fazia no início: vai dançando conforme a música. (E5, informação verbal).
}

As participantes da pesquisa (exceto E5) são estudantes que buscam cumprir a obrigatoriedade do estágio, previsto na grade curricular dos cursos de graduação, ou as horas complementares. Essa condição acarreta rotatividade nas escolas, pois há uma troca constante entre os monitores e na assistência aos alunos. No que se refere à formação, as entrevistadas relatam que, antes de iniciarem na sala de aula, recebem somente informações sobre o tipo de deficiência do aluno, como é relatado por El: "[...] me explicou como era, como ele agia, mas cheguei bem despreparada." Com relação a ter alguma capacitação, El refere que "[...] nenhuma, só o que a minha faculdade está me passando. Agora eu estou fazendo a disciplina de políticas pedagógicas e ali inclui muito como tu deves agir com a criança especial, com a inclusão, mas só isso que eu tenho para trabalhar." (informações verbais).

Na legislação existente nos municípios investigados não está prevista a exigência de formação específica na área de educação inclusiva para atuar como PA, não contemplando, também, capacitações para aqueles que desempenham essa função. 0 Plano Estadual de 
Educação prevê a estratégia de criar cargos para as atividades como revisor e transcritor de braile e também para monitores escolares da área de inclusão, sendo efetivados por concursos públicos, tendo como exigência formação em curso técnico em educação (RIO GRANDE DO SUL, 2015). Em uma das cidades pesquisadas, apesar de não possuírem formação para atuar na inclusão, os estagiários recebem cursos, como refere E4:

\footnotetext{
[...] ano passado nos proporcionaram um curso para monitoria de inclusão. Então foi muito importante a gente ter experiência de outros monitores, tempo de conversar sobre isso, porque eu cheguei aqui sem experiência nenhuma. [...] Cada semana um profissional de uma área diferente ia falar [...] então assim a gente conseguia a cada semana trabalhar um assunto diferente, trazia as suas experiências, a gente formava grupos e apresentava lá na frente, falava sobre como funcionava, foi uma troca muito legal. (E4, informação verbal).
}

A entrevistada salienta que antes do curso já havia estabelecido contato com outros monitores, já que não possuía nenhuma formação ou experiência anterior. Entre os assuntos abordados, dialogavam sobre as dificuldades que cada um enfrentava e trocavam ideias de atividades com os alunos, compartilhando suas experiências. A partilha das experiências, que é relatada por E4, é vista como facilitadora da inserção dos monitores na realidade escolar e como fomento de novas práticas. Evidencia-se, mais uma vez, a partir do entendimento da necessidade das participantes de se capacitarem pedagogicamente, que elas se identificam como professoras e não como profissionais de apoio de acordo com a legislação vigente. A partilha de experiências e práticas em sala de aula enseja responder possivelmente às atribuições do professor, não se posicionando como apoio à inclusão, em que as tarefas remeteriam ao cuidado do aluno para sua pertença e acesso na sala de aula.

E5 possui formação para atuar com alunos público-alvo da Educação Especial, sendo a participante que mais possui experiência e privilegia ações de formação contínua:

\footnotetext{
Este ano estou terminando a pós-graduação em gestão do SUS, fazendo educação inclusiva. Fiz um curso de autismo e me inscrevi em um curso em AEE; não foi pelo aluno que eu comecei a fazer um curso. Eu cheguei lá e achei que era bom e comecei a fazer. Com a experiência do aluno e das outras experiências que eu tive, fico pensando: Por que não fiz antes os cursos? Fiz o que podia na época, mas poderia ter feito muito mais. (E5, informação verbal).
}

A partir desse percurso de formação se configura uma atuação bastante ativa do ponto de vista pedagógico em sala de aula, mesmo na condição de PA, quando adapta atividades, formula estratégias lúdicas e conduz a participação de alunos nas tarefas. E2 
menciona que, em sua cidade, é exigido estar cursando o Ensino Superior para atuar como monitor, preferencialmente Pedagogia, não sendo ofertadas capacitações, pois se pressupõe que sejam ofertadas disciplinas de inclusão na graduação. Para E3:

\begin{abstract}
A gente estuda bastante para saber como que é cada caso. Eu até então não sabia; então a gente corre direto para o celular para saber o que cada um deles tem, e saber o que a gente pode e não pode fazer, o que eles gostam e o que eles não gostam que faça. Porque existem vários, tem uns que não gostam que tu fiques sentado muito perto, tem uns que gostam que tu dês atividade e saia. Então tu tens que pesquisar. E como sou nova e ainda estou cursando, eu preciso pesquisar para saber, então, o que eu vou fazer com eles. (E3, informação verbal).
\end{abstract}

Na pesquisa realizada por Martins (2011) foi identificado que a falta de capacitação para os profissionais de apoio dificulta o atendimento aos alunos público-alvo da Educação Especial, pois, para atuar como PA, não é necessária a formação em Educação Especial. Desse modo, os cursos de qualificação seriam essenciais para que o trabalho desenvolvido pelos profissionais de apoio fosse mais eficaz. A entrevistada 5 corrobora essa posição: “[...] vejo a importância de a monitora ter um curso que vai acrescentar na prática mesmo, porque tu fazes a teoria, e aplicar na prática é muito importante." (informação verbal).

Percebe-se que essas concepções contradizem o que foi definido como PA neste artigo, pois o indicativo é de que a atuação dos profissionais de apoio entrevistados não se circunscreve ao auxílio a alimentação, higiene e locomoção, funções previstas para o PA (BRASIL, 2015), diferentemente das potencialidades do professor de apoio ou mesmo do professor regente da classe. Martins (2011) indica que mesmo que haja poucos estudos e normativas sobre o PA, as escolas têm buscado novas alternativas para efetivar a inclusão. Contudo, pode-se refletir se a modalidade de oferta encontrada incide e contribui para a efetividade da inclusão.

0 entendimento sobre sua contribuição e especificidade de atuação enquanto PA, bem como a concepção de inclusão subjacente ao seu fazer na escola são evidenciados nas seguintes declarações: 
É um desafio diário, é muito trabalho, muita dedicação e quando trabalha com criança, tem que ter muita paciência. Mas é muito enriquecedor, eu quis trabalhar com isso para ter uma experiência de ter alguma coisa com criança, para que eu possa talvez focar nisso futuramente na profissão. Mas o que eu ganhei aqui, nesse um ano e meio, eu vou levar para vida, assim, e para o meu cotidiano profissional com certeza. (E4) (informações verbais).

As participantes enfatizam o aprendizado enquanto PA na possibilidade do trabalho com crianças e na aproximação aos alunos público-alvo da Educação Especial. Nessa dimensão, o que está em causa é a relação do profissional com a experiência e não a relação do aluno com a PA, bem como a identificação e a possível resolução de demandas apresentadas pelo aluno. Embora haja o reconhecimento de que se trata de um processo relacional, é importante assinalar que o ganho identificado remete ao desenvolvimento profissional do monitor, havendo um descentramento na função inerente ao apoio, que consideraria primordialmente o aluno ou, até mesmo, a classe em que o profissional atua.

A respeito do lugar que ocupam na interface com o professor, foram compartilhadas as seguintes formulações, que visibilizam o compromisso com a condição pedagógica do aluno a quem assistem em sala de aula:

\begin{abstract}
A gente ouve o termo monitor geralmente [...] eu acho que ele é aquele profissional que busca sempre ajudar o aluno com deficiência no desenvolvimento dele e fazer com que se insira na turma. Ele não vai fazer as coisas para o aluno, ele vai ajudar o aluno a fazer aquela atividade, vai buscar melhorar o aprendizado do aluno, ele nunca vai fazer a atividade para o aluno. (E2).

Eu penso que é o que eu faço, é adaptar o máximo possivel a aula do outro professor para que ele fique mais dentro naquela realidade. Além de fazer essa adaptação, usar outros jogos, outras coisas que, quando naquela hora, que ele não consegue entrar naquela adaptação, que sirvam de apoio para a alfabetização no caso dele. (E5, grifo nosso) (informações verbais).
\end{abstract}

A condição da atuação do PA descrita anteriormente presume uma apropriação sobre a dinâmica da aprendizagem a ser garantida ao estudante, bem como um protagonismo significativo na condução desse processo. A indagação sobre essa potência é formulada por E1, reposicionando o lugar do PA, especialmente em sua interlocução com o professor:

Deveria ser alguém que apoia o professor titular. Eu acredito que ele deve apoiar, ele fica diretamente com a criança, mas deve apoiar, quem tem que trazer tudo para o aluno é o professor titular. Eu acho que tu estás apoiando, tu vês como que está o desenvolvimento e passa para o 
professor, que querendo ou não tu que vai ter um contato mais direto com ele porque tu já estás ali sempre do lado. (E1) (informação verbal).

Analisando na íntegra as entrevistas, nenhuma das participantes relata a realização das atividades de higiene, locomoção e alimentação, funções que são atribuídas ao PA. As PAs referem-se ao PA como alguém diretamente responsável pelo aluno, sendo apoio para o desenvolvimento do sujeito, adaptando ou propondo atividades. As menções ao trabalho realizado não apontam referências teóricas, normativas legais ou institucionais, bem como articulações com o conhecimento advindo da formação universitária. Schreiber (2012) identificou que a falta de planejamento conjunto entre o professor titular e o PA reflete no desenvolvimento pedagógico individualizado em sala de aula com o aluno público-alvo da Educação Especial. 0 professor regente, ao não compreender a função do PA, atribui a este a adaptação das atividades para o aluno público-alvo da Educação Especial. Fonseca (2016) verificou as múltiplas funções que o PA tem assumido no ambiente escolar, atribuições que vão além das previstas na legislação, ocorrendo indefinição relativa também à formação para trabalhar nesse campo.

A Legislação não prevê que o PA desempenhe funções pedagógicas (BRASIL, 2015), mas as entrevistadas situam sua atuação no auxilio às professoras regentes. E2, quando começou a atuar como monitora, não participava das reuniões de planejamento, a professora informava o conteúdo a ser estudado pelo aluno público-alvo da Educação Especial e indicava como ela deveria explicar e conversar com ele sobre os conteúdos: “[...] trazia atividade e passava para eu passar para ele. A avaliação eu fazia e passava para ela também [...] ela também estava sempre acompanhando. Sempre que encontrava uma dificuldade eu falava para ela, para ela tentar resolver aquele problema." Com relação à comunicação existente entre ela e a professora, E2 acrescenta "[...] ela perguntava: Eu trouxe tal atividade, tu achas que ele vai conseguir? Eu dizia acho que sim, acho que não. Às vezes ela pedia: 'Tu tens alguma ideia, traz que a gente faz com ele.' A professora era bem acessivel nessa questão." (informações verbais). Nesse relato fica bastante evidente a mediação realizada pela PA com relação às tarefas e mesmo à aprendizagem do aluno, configurando a restrita interação da professora com o aluno e, consequentemente, sua ausência para propor e avaliar o desenvolvimento do estudante.

Nesse contexto, surgem as diferenças no que diz respeito à condução do processo de adaptação curricular, que repercute nas atribuições que as PAs desempenham.

Ano passado era mais fácil, porque a professora era outra, era diferente. Mas a professora desse ano tem formação para trabalhar com criança especial, só que eu acho mais complicado, porque ela uniformiza: ela tem duas crianças especiais na mesma sala, com deficiências diferentes. Um 
tem síndrome de Williams, e o outro tem espectro autista, e ela uniformizou: o que ela está trabalhando com um ela está trabalhando com outro, e o desenvolvimento psicomotor e tudo é totalmente diferente um do outro. [...] cada professor trabalha de um jeito: ano passado era $\circ \mathrm{l}$. que tinha um currículo adaptado e a M. tinha outro porque ela entrou nessa escola. Ela estava matriculada em outra escola no outro município dela, mas ela nunca frequentou. Então ela não sabia pegar um lápis, não sabia pegar um giz. [...] A gente tem que prestar mais a atenção nisso para conseguir trabalhar com a criança. (E1) (informação verbal).

Diante do contexto que El descreve, a PA relata propor alternativas para potencializar a aprendizagem dos alunos, como a busca de materiais para a compreensão de conteúdos de matemática ou o uso de pintura como recurso de expressão gráfica, iniciativas que avalia como promissoras para o acompanhamento dos alunos. Na situação vivenciada por E3, os professores repassam o que vai ser trabalhado pelo PA antecipadamente, para que este tenha ciência e saiba como apresentar a tarefa ao aluno. A instrução é de que os alunos realizem, sempre que puderem, a atividade com os colegas: "Eles não vão fazer uma coisa separada, sendo que a gente sabe que eles podem fazer. Claro que eles vão precisar de um pouco de ajuda, mas eles têm que estar sempre junto com os colegas. Eles não podem estar em turmas separadas." (E3) (informação verbal). Pode-se refletir o quanto esse compartilhamento se restringe ao espaço físico, pois ensejaria outras trocas e mediações para a realização das atividades, mesmo entre o professor e o aluno, para ser efetiva. E4 dimensiona o momento em que a participação na turma do aluno assistido ocorre:

\footnotetext{
Ele está no processo de alfabetização. A maioria das atividades que ele faz é o que a turma faz também, então a gente consegue dar andamento meio que junto. Em determinados momentos, quando a gente entra no processo de escrever, que ele não consegue, a cognição dele é afetada. Então a gente acaba fazendo uma atividade mais tranquila com ele. Nesse momento fica só eu e ele, e deixo a turma trabalhar mais individual; mas na maioria das vezes acaba funcionando bem assim, porque ele mesmo quer terminar aquela atividade logo para poder ficar com a turma de novo e fazer atividade junto. (informação verbal).
}

A descrição sugere que a partilha entre o aluno atendido pela PA e a turma comporta mais a conjunção dos tempos de realização das atividades do que a construção do conhecimento atinente ao conteúdo. 0 impedimento com relação à escrita é entendido como uma limitação do aluno, algo de sua condição, que é resolvido com a troca de atividades. Se há uma proposição reconhecidamente pedagógica no acompanhamento, a intervenção não observa recursos ou estratégias que potencializem efetivamente o aprendizado, situando a dificuldade como oportunidade de desenvolvimento. Ademais, quanto à pertença do aluno na 
classe, configura como presença por meio de atividades/práticas em paralelo, não havendo experiência de monitoria com seus pares ou a consecução da adaptação curricular.

E5 adapta a aula do professor regente conforme as condições que identifica pertinentes para o aluno participar da aula: "Trago várias atividades, como de vogais, de alfabeto, de pintura, de recorte. Eu tenho sempre na minha mochila, porque conforme a aula que o professor dá, incluo o que tenho ali. Aí fica mais fácil de fazer com que ele fique integrado naquela turma." A entrevistada faz um planejamento para as aulas em casa, para não ficar perguntando para o professor: "Porque eu tenho outra turma à tarde, e ele também tem outra turma. A gente não tem esse tempo de estar programando o que tu vais dar e o que eu vou dar, então eu já me adianto." (informações verbais). Os relatos indicam a participação ativa do PA no ensino e na aprendizagem dos alunos com deficiência, sinalizando mais uma vez a inexistência de planejamento em conjunto entre professor regente e monitor, refletindo uma compreensão peculiar sobre as funções exercidas pelo PA. No Plano Estadual de Educação (RIO GRANDE DO SUL, 2015) estão previstas a promoção e a inclusão de referenciais teóricos sobre os processos de ensino e aprendizagem que se referem ao atendimento educacional dos sujeitos público-alvo da Educação Especial nos cursos de licenciatura, bem como a capacitação de monitores para o atendimento desses estudantes. A diretriz é fundamental para fomentar o conhecimento dos profissionais da educação sobre as práticas pedagógicas e a legislação atinente à Educação Especial, podendo vir a questionar e ressituar a relação estabelecida dos docentes com os profissionais de apoio, bem como as responsabilidades de ambos diante da aprendizagem dos alunos.

As entrevistadas situam questões relativas aos materiais existentes e aos recursos necessários para a atuação junto aos alunos. Para E2, a escola tinha muitos recursos, materiais lúdicos e materiais somente de inclusão e acrescenta que também seria bom para melhorar o seu trabalho "Algum curso de capacitação, que oferecesse um cursinho básico, mas acho que vale o profissional buscar também." (informação verbal). E4 menciona, também a importância do compartilhamento de conhecimento e outros apoios aos alunos para desenvolvimento de suas atividades:

Um acompanhamento por fora é o que a gente sempre procura. Quando esses tipos de alunos inclusos chegam, a gente sempre quer saber se eles estão com acompanhamento psicológico, se eles tomam medicação, como que funciona essa rotina fora da escola. Porque não adianta a gente tentar fazer uma rotina, dar limites, ensinar todo um modo de trabalhar aqui dentro, e depois lá fora isso não vai ter progresso. Então acompanhamento psicológico para esse tipo de criança é muito importante, para que a gente consiga trabalhar junto. (E4) (informação verbal). 
E1 considera que a disponibilidade de recursos tecnológicos, como um tablet, faria a diferença na assistência à aluna que acompanha, mas reconhece que a biblioteca da escola possui muitos livros e jogos, o que é um diferencial, sendo uma instituição do interior do Estado. Segundo Conte e Basegio (2015), os recursos materiais e tecnológicos são essenciais, e no ambiente escolar as tecnologias assistivas podem ser inseridas para ultrapassar barreiras e criar novos paradigmas de informação, permitindo aos alunos da Educação Especial participar, interagir e aprender. E5 enfatiza que a sala do AEE possui vários recursos, mas é um espaço utilizado por outros alunos, assim como a biblioteca, onde nem sempre há condições para atender o aluno. "Então, se tivesse uma sala que tivesse todos os recursos, que estivesse ali seria melhor." E5 afirma que não ter uma sala faz com que enfrente alguns constrangimentos: "Tu tens que entrar nos espaços dos outros, e também há aquela crítica das outras pessoas, porque aquelas que não fizeram o curso acham que aquilo é só diversão." (informações verbais). Importante considerar que, nos contextos mencionados pelas participantes, a condução da aprendizagem é sugerida como algo da interação entre PA e aluno, dissociando essa potencialidade dos demais dispositivos e profissionais atuantes na escola, o que circunscreve a ação em âmbito deveras restrito diante da possível circulação dos alunos por outras interfaces e profissionais.

Ao ser evidenciada a atuação do PA com contornos significativamente pedagógicos, a partir dos elementos analisados, pode-se avaliar que a presença do aluno público-alvo da Educação Especial na escola está bastante fundada na vinculação com o PA. Considerando que, dentre os profissionais pesquisados, predominam estudantes de cursos de graduação em contratos de estágio como monitores, não há formação e experiência dos profissionais com relação à Educação Especial, bem como se trata, muitas vezes, da primeira experiência de trabalho em ambiente escolar. Nesse contexto evidenciado, somase a postura dos professores titulares que, muitas vezes, delegam ao PA a condução da escolarização do aluno público-alvo da Educação Especial, não havendo evidências da efetiva adaptação curricular. Decorrem, portanto, várias implicações no processo de ensino e aprendizagem, em função da não vinculação do professor regente com os alunos atendidos pelas PAs, remetendo a elas o acompanhamento do processo educativo. Evidencia-se o concomitante isolamento e a individualização das atividades realizadas pelas profissionais que são concebidas majoritariamente para a vinculação ao aluno público-alvo da Educação Especial, o que não concorre para a inclusão, pois se centra nessa relação dual. Ademais, no âmbito escolar a experiência é concebida como uma diferença e não como uma expressão da diversidade, o que não potencializa o aprendizado para a classe e a comunidade escolar como um todo. 


\section{CONSIDERAÇÕES FINAIS}

A partir do relato das participantes e dos documentos analisados foram identificadas as matrículas dos alunos público-alvo da Educação Especial em salas de aula regulares acompanhados por profissionais de apoio. Contudo, face às múltiplas concepções de inclusão possivelmente existentes, a diversidade das ações e dos propósitos dos apoios oferecidos ocasiona uma dispersão de esforços atribuidos ao processo de ensino e aprendizagem desses alunos. A restrita articulação da PA com a professora, com a equipe pedagógica da escola e mesmo com outros alunos indica uma atuação, muitas vezes, guiada pelas iniciativas individuais, na tentativa de responder pelo desenvolvimento educacional do estudante. A função de apoio, descrita na Legislação Brasileira de Inclusão (BRASLL, 2015), distancia-se das atividades desempenhadas pelas participantes da pesquisa, concorrendo para a construção de um vínculo majoritário na relação do aluno com a escola, a partir de conhecimentos pedagógicos não atinentes a sua formação e atuação.

0 contexto da atuação do PA investigado reflete o cenário de construção da escola para todos no País. Há a criação de dispositivos legais, muitas vezes, desacompanhados de politicas de formação dos profissionais da escola, os quais, por sua vez, não participam da construção das potencialidades e ações que asseguram a inclusão. $0 s$ diversos contextos educacionais presentes nas cidades brasileiras precisam ser analisados para que se visibilizem as diferentes dimensões que a experiência da inclusão provoca e evoca, de modo a comprometer toda a comunidade escolar. Busca-se, nessa direção, que a criação de cargos e recursos não fragmente a proposta de atendimento ao aluno público-alvo da Educação Especial, mas, contrariamente, concretize uma possibilidade de atuação multiprofissional em rede.

\section{REFERÊNCIAS}

ARAÚJO, L. A.; XAVIER, B. R. X:; FRETAS, R. C. A precariedade do fornecimento de PA educacional ao aluno com deficiência em Fortaleza/CE. IN: SEMINÁRIO LUSO-BRASILEIRO DE EDUCAÇÃO INCLUSIVA: 0 ENSINO E A APRENDIZAGEM EM DISCUSSÃO, 1., 2017, Porto Alegre. Anais [...] Porto Alegre, 2017. Disponivel em: http://ebooks.pucrs.br/edipucrs/anais/i-seminario-luso-brasileiro-de-educacao-inclusiva/assets/ artigos/eixo-1/completo-4.pdf. Acesso em: 28 jan. 2019.

BRASIL. Constituição. República Federativa do Brasil de 1988. Brasilia, DF: Senado Federal, 5 out. 1998. Disponivel em: http://www.planalto.gov.br/ccivil_03/constituicao/constituicaocompilado.htm. Acesso em: 23 jan. 2019.

BRASIL. Lei n. 9.394/96, de 20 de dezembro de 1996. Estabelece as Diretrizes e bases da educação nacional. Diário Oficial da União, Brasilia, DF, 21 dez. 1996. Disponivel em: http://www.planalto.gov.br/ ccivil_03/LEIS/L9394.htm. Acesso em: 23 jan. 2019. 
BRASIL. Lei n. 13.005, de 25 de junho de 2014. Aprova o Plano Nacional de Educação - PNE e dá outras providências. Diário Oficial da União, Brasília, DF, 26 jun. 2014. . Disponível em: http://pne.mec.gov.br/18-planos-subnacionais-de-educacao/543-plano-nacional-de-educacao-lei-n-13-005-2014. Acesso em: 2 fev. 2019.

BRASIL. Lei n. 13.146, de 6 de julho de 2015. Institui a Lei Brasileira de Inclusão da Pessoa Com Deficiência. Diário Oficial da União, Brasília, DF, 6 jul. 2015. Disponível em: http://www.planalto.gov.br/ ccivil_03/_ato2015-2018/2015/lei/113146.htm. Acesso em: 23 jan. 2019.

BRASIL. Parecer CNE/CEB 17/2001. Diretrizes Nacionais para a Educação Especial na Educação Básica. Diário Oficial da União, Brasilia, DF, 17 ago. 2001. Disponível em: http://portal.mec.gov.br/cne/arquivos/ pdf/CEB017_2001.pdf. Acesso em: 17 jan. 2019.

BRASIL. Ministério da Educação. Nota Técnica n. 19, 8 de setembro de 2010. Profissionais de apoio para alunos com deficiência e transtornos globais do desenvolvimento matriculados nas escolas comuns da rede pública de ensino. Ministério da Educação, Brasilia, DF: MEC: SEESP: GAB, 8 set. 2010. Disponível em: http://portal.mec.gov.br/index.php?option=com_docman\&view=download\&alias=17237-secadi-documento-subsidiario-2015\&ltemid=30192. Acesso em: 30 jan. 2019.

BRASIL. Ministério da Educação. Nota Técnica n. 24, de 21 de março de 2013. Orientação aos sistemas de ensino para a implementação da Lei n ^ 12.764/2012. Brasília, DF: MEC: SEESP: GAB, 21 mar. 2013. Disponivel em: http://portal.mec.gov.br/index.php?option=com_docman\&view=download\&alias=13287-nt24-sistem-leil2764-2012\&category_slug=junho-2013-pdf\&ltemid=30192. Acesso em: 27 jan. 2019.

BRASIL. Ministério da Educação. Política nacional de educação especial na perspectiva da educação especial. [Brasilia, DF]: MEC/SECADI, 2008. Disponível em: http://portal.mec.gov.br/index. php?option=com_docman\&view $=$ download\&alias $=16690$ - politica-nacional-de-educacao-especial ${ }^{-n{ }^{-}}{ }^{-}$ -perspectiva-da-educacao-inclusiva-05122014\&ltemid=30192. Acesso em: 28 jan. 2019.

BRASIL. Resolução n. 4, de 2 de outubro de 2009. Institui Diretrizes Operacionais para o atendimento educacional especializado na Educação Básica, modalidade Educação Especial. Diário Oficial da União, Brasilia, DF, 3 out. 2009. Disponível em: http://portal.mec.gov.br/dmdocuments/rceb004_09.pdf. Acesso em: 28 jan. 2019.

CARVALHO, M. C. N. Professores de apoio educativo- mediadores? Como? Quando? 2009. 624 f. Dissertação (Mestrado em Ciências da Educação) Universidade de Lisboa, Lisboa, 2009.

CONTE, E;; BASEGIO, A. C. Tecnologias assistivas: recursos pedagógicos para a inclusão humana. Revista Temas em Educação, João Pessoa, v. 24, n. 2, p. 28-44, jul./dez. 2015. Disponível em: https:// www.periodicos.ufpb.br/index.php/rteo/article/view/20242. Acesso em: 23 jan. 2019.

FONSECA, M. Das políticas públicas de inclusão escolar à atuação do PA/monitor. 2016 . 95 f. Dissertação (Mestrado em Educação) - Universidade Federal de Santa Maria, Santa Maria, 2016. 
FONSECA, M.; BRIDI, F. R. S. A atuação do PA/monitor na rede privada de ensino. In: REUNIÃO CIENTIIFICA REGIONAL DA ANPED, 11., 2016, Curitiba. Anais [...] Curitiba, 2016. Disponível em: http://www.anpedsul2016. ufpr.br/wp-content/uploads/2015/11/eixo22_MANOELA-DA-FONSECA-FABIANE-ROMANO-DE-SOUZA-BRIDl.pdf. Acesso em: 23 jan. 2019.

FONTANELLA, B. J. B.; RICAS, J.; TURATO, E. R. Amostragem por saturação em pesquisas qualitativas em saúde: contribuições teóricas. Caderno de Saúde Pública, Rio de Janeiro, v. 24, n. 1, p. 17-27, 2008. Disponivel em http://www.scielo.br/scielo.php?script=sci_arttext\&pid=S0102-311X2008000100003. Acesso em: 28 jan. 2019.

FREITAS, A. O. Atuação do professor de apoio à inclusão e os indicadores de ensino colaborativo em Goiás. 2013. १२3 f. Dissertação (Mestrado em Educação) - Universidade Federal de Goiás, Catalão, 2013.

FROHLICH, R. Práticas de apoio à inclusão escolar e a constituição de normalidades diferenciais. 2018. 221 f. Tese (Doutorado em Educação) - Universidade do Vale do Rio dos Sinos, São Leopoldo, 2018.

GARCIA, R. M. C. Educação especial na perspectiva inclusiva: determinantes econômicos e políticos. Comunicaç̃es, Piracicaba, v. 23 n. 3, p. 7-26, 2016. D0l 10.15600/2238-121X/comunicacoes.v23nespp7-26.

GARCIA, R. M. C. Política de Educação especial na perspectiva inclusiva e a formação docente no Brasil. Revista Brasileira de Educação, Rio de Janeiro, v. 18, n. 52, p. 101-110, jan./mar. 2013. Disponível em: http://www.scielo.br/pdf/rbedu/v18n52/07.pdf. Acesso em: 18 jan. 2019.

GIL, A. C. Métodos e técnicas de pesquisa social. 6. ed. São Paulo: Atlas, 2012.

INEP. Censo Escolar da Educação Básica 2017. [S. l]: INEP, 2018. Disponivel em: http://download.inep. gov.br/educacao_basica/censo_escolar/notas_estatisticas/2018/notaestatisticas_Censo_Escolar_2017.pdf. Acesso em: 24 nov. 2018.

INEP. Censo Escolar da Educação Básica 2018. [S. l]: INEP, 2019. Disponível em: http://portal.inep.gov.br/ web/guest/sinopses-estatisticas-da-educacao-basica. Acesso em: 25 jan. 2020.

MACEDO, M. D. C. S. R. et al. Histórico da /inclusão escolar: uma discussão entre texto e contexto. Psicologia em Estudo, Maringá, v. 19, n. 2, p. 179-189, abr./jun. 2014. Disponível em: http://www.scielo.br/ scielo.php?script=sci_arttext\&pid=S1413-73722014000200002. Acesso em: 25 jan. 2020.

MARCONI, M. A.; LAKATOS, E. M. Fundamentos de metodologia científica. 5. ed. São Paulo: Atlas, 2003.

MARTINS, S. M. 0 PA na rede regular de ensino: a precarização do trabalho com os alunos da Educação Especial. 2011. 168 f. Dissertação (Mestrado em Educação) - Universidade Federal de Santa Catarina, Florianópolis, 2011.

MOUSINHO, R. et al. Mediação Escolar e inclusão: revisão, dicas e reflexões. Revista de Psicopedagogia, São Paulo, v. 27, n. 82, p. 2-8, 2010. http://pepsic.bvsalud.org/scielo.php?script=sci_arttext\&pid $=$ S0103-84862010000100010. Acesso em: 28 jan. 2019. 
RIO GRANDE DO SUL. Lei n. 14.705 de 25 de junho de 2015. Institui o Plano Estadual de Educação. Diário Oficial do Estado, Porto Alegre, 25 jun. 2015. Disponivel em: http://www.al.rs.gov.br/filerepository/ repLegis/arquivos/LEl\%2014.705.pdf. Acesso em: 24 nov. 2018.

SCHREIBER, D. V. F. A. Política educacional, trabalho docente e alunos da modalidade educação especial: um estudo nos anos iniciais do ensino fundamental. 2012. 239 f. Dissertação (Mestrado em Educação) - Universidade Federal de Santa Catarina, Florianópolis, 2012.

SILVA, K. F. W.; MACIEL, R. V. M. Inclusão escolar e a necessidade de serviços de apoio: como fazer? Revista Educação Especial, Santa Maria, p. 107-115, 2011. https://periodicos.ufsm.br/educacaoespecial/article/view/4405/2578. Acesso em: 24 nov. 2018.

STEIN, E. Aproximações sobre hermenêutica. 2. ed. Porto Alegre: EDIPUCRS, 2004.

VEIGA-NETO, A.; LOPES, M. C. Inclusão, exclusão, in/exclusão. Verve, n. 20, p. 121-135, 2011.

Endereço para correspondência: Avenida Victor Barreto, 2288, Centro, Canoas, Rio Grande do Sul, Brasil; amandaburchert@gmail.com

Roteiro, Joaçaba, U. 45, p. 1-24, jan./dez. 2020 | e21096 |E-ISSN 2177-6059 
